\title{
Clinical Issues and Treatment of Lung Cancer in Mexico
}

\author{
Rufino Echegoyen-Carmona*, Daniel Mendoza-Posada, Catalina Camacho-Mendoza and \\ Oswaldo Rafael Sánchez-Campos
}

\author{
Lung Oncology, National Respiratory Diseases Institute (INER), Mexico City
}

\begin{abstract}
Retrospective analysis of 101 lung cancer patients treated at the INER [National Respiratory Diseases Institute] in Mexico from January 2006 to October 2007.
\end{abstract}

Objective: Analysis of clinical situation and treatment.

Results: The study comprised 59 men and 42 women: $58 \%>60$ years old. $14.8 \%$ were non-smokers or had no smoking history. $85.2 \%$ were heavy smokers with a smoking history above 15 packs per year.

Eleven patients had one family member with cancer. $86.1 \%$ of them were admitted to hospital when the tumor stage was between IIIA and IV. 21 patients of this group had metastasis. 86.1\% had an ECOG grade of 0.2.

Two analytical parameters were handled: RECIST and the media overall survival.

93 of 101 patients $(92 \%)$ were treated with chemotherapy: 51 of them $(54.7 \%)$ with Cisplatine and Paclitaxel, $29(31.1 \%)$ with Cisplatine and Vinorrelbine, and $13(13.8 \%)$ with Cisplatine and Gemcitabine, each one for 2 to 6 cycles. According to RECIST, 6 patients had a complete response, 19 had progressions with distal metastasis, and 68 had partial responses. The median overall survival was of $17.0,18.4$, and 16.1 months, respectively.

Chirurgic intervention was carried out in 8 patients, lobectomy in 7 patients, and one had a pneumonectomy with resection of mediastinal lymph nodes and adyuvant chemotherapy. Histopathology of the lymph nodes and bronchial section were negative for neoplasia. The disease-free survival was 13 to 25 months in lobectomies and 22 months in the pneumonectomy. The cause of dead could not be specified because they did not continue attending post-treatment control.

Conclusion: Lack of Health Education amongst patients and their families was found to be a major cause which prevented a more effective result of the treatment. This study also concludes that a multidisciplinary treatment for lung cancer patients is required.

Keywords: Metastasis, median overall survive, adyuvant chemotherapy.

\section{INTRODUCTION}

The worldwide highest mortality due to any cancer was 7.9 million in 2007. Lung cancer was the first cause of death in men whereas breast cancer was the main cause of death in women. In the USA approximately 170000 new cases were diagnosed in 2003; in the European Union, a figure of at least 200 000 was recorded [1]. In Mexico, 1019 patients with lung cancer were reported by the INER from 1984 to 1992 [2] Ruiz G. L. indicated that 397,400 deaths were produced between 1984-1992 by malignant neoplasms, $45578(11.5 \%)$ of these were identified as lung cancer [3]. In in 2007, the National Institute of Statistics, Geography and Informatics (INEGI in its Spanish acronym) reported 149520 lung cancer cases in Mexico [4].

From a clinical point of view, lung cancer includes two important varieties: $80 \%$ consists of non-small cell

*Address corresponding to this author at the Lung Oncology, National Respiratory Diseases Institute (INER), Mexico City; Tel: + 5255566645 39; Fax: + 525515568178 ;

Echegoyen-Carmona, E-mail rufino.echegoyen@gmail, com;

Mendoza-Posada, E-mail danielm3742@gmail.com;

Camacho-Mendoza, E-mail quimi_iner@live.com.mx;

Sánchez-Campos, E-mail magodeozxxx@yahoo.com.mx lung cancer (NSCLC), including the subtypes of squamous-cell carcinoma, adenocarcinoma, and largecell carcinoma and $20 \%$ consists of small cell cancer (SCLC). In the NSCLC group, the most important varieties of histological cancers are the squamous-cell cancer and the adenocarcinoma cancer [5]. Almost $70 \%$ of the malignant neoplasms are diagnosed at advanced stages. For this reason mortality figures were high in many countries [6].

In the Oncology warden of the INER, the following general characteristics were noticed amongst lung cancer patients: a) in advanced stages of their illness b) response to chemotherapy was variable $c$ ) patients often stopped their treatments after experiencing clinical improvements d) and they did not conclude their treatments d) metastatic non-small cell lung cancer remissions were experienced f) patients did not attend regularly their periodical controls.

This situation encouraged us to produce this retrospective study with the aim of analyzing the clinical conditions, treatment and overall survival of the overall survival of 112 patients with non-small cell lung cancer treated at the INER between January 2006 and 
October 2007 in order the find key factors or possible solutions to improve the results of the treatment.

\section{METHODOLOGY}

112 patients with non-small cell lung cancer were treated at the INER between January 2006 and October 2007. 11 of those patients were excluded from this study because 8 were terminal cases when they became inpatients, 2 did not accept the proposed treatment, and 1 did not have the histopathologic confirmation of non-small cell lung cancer. Thus, this study comprises 101 patients with verified NSCLC histopathology who were treated at our hospital.

The consideration of their clinical situation included the following information: gender, age, smoking habits, symptomology, cancer genetic loading, imaging and laboratory studies, bronchoscopy, and lung or surgical piece biopsy histopathology. The patients were divided in two groups: $93(92.0 \%)$ were treated with chemotherapy, and $8(7.9 \%)$ were treated with surgery and adyuvant chemotherapy.

The disease was quantified according to Mountain TNM classification $\left(6^{\text {th }}\right.$ edition) and the physical condition of the patients was evaluated in terms of the ECOG scale

The first row of chemotherapy consisted of Cistplatine combined with the following antineoplasic drugs: Paclitaxel, Vinorrelbine or Gemcitabine during 4 or 6 cycles of standard doses. $51(54.7 \%)$ patients received Cisplatine / Paclitaxel, 29 (31.1\%) patients were given Cisplatine / Vinorrelbine, and 13 (13.8\%) patients received Cisplatine / Gemcitabine.

10 patients, who were stable after the first treatment, received a second row of Cisplatine and another antineoplasic during 4 cycles at standard doses.

The results were valued according to RECIST criteria: CR (complete response), clinical improvement of the patients with not visible radiographic lesions; PR (partial response) clinical improvement and 20\% decrease in the sum of lesions; PD (progressive disease) symptoms persisted and the size of lesions increased or metastases was found.

Given the fact that presently the final objective of the treatment is to prolong the patient's survival, the median overall survival was chosen to measure the final response to the treatment. In those cases where the patients stop attending the INER and receiving their treatment, attempts were made to contact them through phone calls. 2 patients were even visited at home. When it was not possible to contact them again, their last attendance to the INER was considered the end of their treatment.

8 patients $(7.9 \%)$ with stages IA to IB and ECOG 01 were treated with lung surgery and adyuvant chemotherapy. Lobectomy was carried out in 7 of them. 1 had pneumonectomy. Surgery included resection of mediastinal lymph nodes. The adyuvant regimen was Cddp/Vino in 5 cases and Cddp/Gem in 3 for 4 cycles at standard dosage. The hystopathology of mediastinal lymph nodes and the bronchial section were negative for neoplasm. Histopathological examination of the surgical pieces and the mediastinal lymph nodes was carried out.

\section{RESULTS}

From the clinical point of view, NSCL was most frequently found $(58.4 \%)$ in male patients with an average age of 60 years-old. Amongst female patients, (41.5\%), cancer was detected a decade earlier Table 1. $15(14.8 \%)$ patients had no smoking habits. $85.2 \%$ were heavy smokers with a smoking history between 5 and 10 packs per year. The smoking history was higher amongst male patients. 11 patients $(10.8 \%)$ had one family member with some kind of cancer.

Table 1: Lung Cancer in Mexico Gender \& Age

\begin{tabular}{|c|c|c|c|}
\hline Gender & Number & $\%$ & Average Age \\
\hline \hline Male & 59 & 58.4 & 58 years-old \\
\hline Female & 42 & 41.5 & 47 years-old \\
\hline Total & 101 & 100.0 & $>60$ years old $58 \%$ \\
\hline
\end{tabular}

Forty seven of them (86.1\%) were admitted to hospital when the tumor stage was between IIIA and IV. 21 patients in this group had metastasis: 6 in pleura and miocardio and 15 with distant metastases. From these, 5 patients had metastasis in the bones, 3 in the liver, 2 in the brain, and 5 in extrathoracic limph nodes. The ECOG ranged between $1-3$ in $80(72.2 \%)$ patients Table 2.

Amongst the 51 patients treated with a standard dose of Cisplatine/Paclitaxel for 4-6 cycles, 2 had a Complete Response (2.1\%), 38 had a Partial Response (40.8\%), and $11(11.8 \%)$ had Progression of the disease. A standard dose of Cisplatine/Vinorrelbine was given to 29 patients during 4-6 cycles. Complete 
Table 2. Lung Cancer in Mexico

\begin{tabular}{|c|c|c|c|c|c|c|c|}
\hline \multicolumn{2}{|c|}{ TNM CLASSIFICATION } & \multicolumn{3}{c|}{ ECOG } & \multicolumn{2}{c|}{ METASTASIS } \\
\hline Stage & Number & $\%$ & Degree & Number & $\%$ & Type & Number \\
\hline \hline IA a IIB & 14 & 13.8 & 0 & 21 & 20.1 & No metastasis & 0 \\
\hline IIIA a IIIB & 45 & 44.5 & $1-2$ & 66 & 65.3 & Localized & 6 \\
\hline IV & 42 & 41.5 & 3 & 14 & 13.8 & Disseminated & 15 \\
\hline Total & 101 & & & 101 & & 21 \\
\hline
\end{tabular}

Response was obtained in 3 patients (10.3\%), Partial Response in 22 (75.8\%), and Progression in 4 (13.7\%). 13 patients were given standard doses of Cisplatine/Gemcitabine for 4-6 cycles. there was one patient with Complete Response (7.6\%), 8 Partial Responses (61.5\%) and 4 Progressions (30.7\%) Table 3.

10 patients received another row of a standard dose of Cisplatine plus another antineoplasic during 4 cycles. The disease was stable at variable times in 68 patients.

According to RECIST, considering the results of the three therapeutic schemes, 6 (6.4) patients had Complete Response; 68 (73.1\%) had Partial Responses, and 19 (20.4\%) Progressions. Amongst the later, 10 had distal metastasis: 4 in cervical or supracervical nodes, 3 in the brain, 2 in the bones, and 1 in the liver.

The median overall survival was 17.0 months in 51 patients treated with Cddp/Taxol regimen, 18.4 months for those with Cddp/Vino, and 16.1 months for the 13 patients with Cddp/Gem Table 4.
The vinorrelbine, gemcitabine or placlitaxel with cisplatine gave similar results and their prescription was in relation to the economic possibilities of the patients. The response to the treatment according to RECIST criteria and the media overall survival was directly proportional to the cycles applied. The response also improved when a second therapeutic row was prescribed.

Chemotherapy for elderly patients has been questioned due to its potential higher toxicity and comorbidities related to age $[7,8]$.

Surgery and Adyuvant Chemotherapy: The patients treated with surgery and adyuvant chemotherapy were admitted to hospital in a good general condition (ECOG $0-1)$ at early stages of the disease (IA-IB). The resicated pieces and the mediastinal nodes were sent to histopathological study.

The patients had no complications. Four patients were alive at the end of this study. The disease free survival was 13 to 25 months in lobectomies and 22 months in the case of pneumonectomy. 4 patients were alive and 4 patients died. The cause of their dead could

Table 3: Lung Cancer in Mexico Treatment \& Recist

\begin{tabular}{|c|c|c|c|c|c|c|c|c|}
\hline Chemotherapy & Number & \% & CR & \% & PR & \% & P & \% \\
\hline \hline CDDP/TAXOL & 51 & 54.8 & 2 & 2.1 & 38 & 40.8 & 11 & 11.8 \\
\hline CDDP/NINO & 29 & 31.1 & 3 & 3.2 & 22 & 23.6 & 4 & 4.3 \\
\hline CDDP/GEM & 13 & 13.9 & 1 & 1.0 & 8 & 8.6 & 4 & 4.3 \\
\hline Total & 93 & 100.0 & 6 & 6.3 & 68 & 73.0 & 19 & 20.4 \\
\hline
\end{tabular}

$\mathrm{CR}=$ complete response, $\mathrm{PR}=$ partial response, $\mathrm{P}=$ progression.

Table 4: Lung Cancer in Mexico Treatment \& Survival

\begin{tabular}{|c|c|c|c|c|c|c|c|c|c|}
\hline & \multicolumn{2}{|c|}{ CHEMOTHERAPY } & \multicolumn{2}{|c|}{ ALIVE } & \multicolumn{2}{|c|}{ DEAD } & \multicolumn{2}{|c|}{$?$} & \multirow{2}{*}{$\begin{array}{c}\text { SURVIVAL } \\
\text { Global Media }\end{array}$} \\
\hline & Num. & $\%$ & Num. & $\%$ & Num. & $\%$ & Num. & $\%$ & \\
\hline CDDP/TAXOL & 51 & 54.8 & 1 & 1.0 & 16 & 17.2 & 34 & 36.5 & 17.0 months \\
\hline CDDP/VINO & 29 & 31.1 & 2 & 2.1 & 10 & 10.7 & 17 & 18.2 & 18.4 months \\
\hline CDDP/GEM & 13 & 13.9 & 1 & 1.0 & 3 & 3.2 & 9 & 9.6 & 16.1 months \\
\hline Total & 93 & 99,8 & 4 & 4.1 & 29 & 31.1 & 60 & 64.3 & \\
\hline
\end{tabular}


Table 5: Lung Cancer in Mexico Surgery \& Adyuvant Chemotherapy

\begin{tabular}{|c|c|c|c|c|c|}
\hline Surgery & Number. & Ady. CHT & CR & ST & V \\
\hline \hline Lobectomy & 7 & CDDP/NINO & 5 & $13-25$ months & 3 \\
\hline Neumonectomy & 1 & CDDP/GEM & 3 & 22 months & 1 \\
\hline
\end{tabular}

$\mathrm{CR}=$ complete Response, ST=Survival time.

not be specified because they did not go back to the INER to continue their post-operatory control. We knew about their dead after we contacted their family via phone calls Table 5.

\section{DISCUSSION}

During our study, we noticed that lung cancer has increased in Mexico over the last decades. The average age of patients diagnosed is 60 years-old. The rate of their smoking habits is high. A contrast between the number of female and male patients shows that the rate of lung cancer of non-small cell is low amongst women. Given the fact that the development of the disease depends on the intensity and chronicity of the habit, the best way to control lung cancer is preventing smoking habits. In Mexico, there are laws and campaigns to control smoking but there have been no clear positive results of these campaigns yet.

$92 \%$ of the patients were admitted to hospital when their disease was already too advanced and they had extrathoracic metastasis. Presently, it is considered that patients at stages IIIB and IV cannot be cured with the chemotherapy available now. Therefore, the aim of the treatment is to prolong their life and ease their symptoms $[9,10,11]$.

Nowadays, surgery, chemotherapy, and radiotherapy are used to treat lung cancer. The treatment should be, as much as possible, multimodal. Surgery continues to be the chosen treatment for nonsmall cell lung cancer (NSCLC) in early stages. However, it demands an early diagnosis and general good condition of the patient because it needs required extension and to include mediastinal lymphatic nodes resection [12].

We have noticed that adyuvant chemotherapy is reassuring for the surgeon and gives confidence to the patient [13].

Oncology surgeons have tried to explain that the remissions after lung resection are due to hidden micrometastases in the mediastinal lymph nodes which cause distal metastases. In our patients with surgical treatment no neoplastic activity in the resected mediastinal lymph nodes was found. Given our reduced number of patients with surgical treatment remains low, we cannot reach specific conclusions. The mediastinal lymph nodes resection remains a controversial topic amongst different authors [14,15].

Micrometastases has been defined as a small tumor deposit 0.2 to 2 milimicres in diameter, usually detected by routine hematoxylin and eosin (HE) staining, that often shows mitoses and invasion. In contrast, isolated tumor cells (ITC) are small clumps of tumor cells, typically without mitoses or vascular or lymphatic invasion within nodes (or distant sites). Micrometastases can be detected by standard histopathology, albeit with lower sensitivity. Therefore, to date, immunohistochemistry $(\mathrm{IHC})$ remains the gold standard for the detection of micrometastases. With typical mitosis and invasion to lymphatic or blood capillaries that distinguish them from isolated tumor cells, small tumoral isolated cell groups without mitosis or lymphatic invasion. This has suggested that at the time of diagnoses NSCLC is a systemic disease [1618].

Taking into account that the stage of lung cancer in our patients was too advanced, that their economic possibilities were very low, and the ECOG, we consider that the results of the treatment were positive in stages IIV and IV. However more accurate date and efficiency in the treatment remains a goal related to health education.

Possible causes that explain the patients did not continue their treatment are:

a) people consider that cancer is a mortal disease, b) doubts regarding the efficiency of the treatment, c) high costs of the treatment, d) lack of understanding and collaboration from the family, e) confusion regarding the fact that improvement does not mean that the disease is cured, f) new symptoms produced by chemotherapy toxicity, g) some patients follow alternative therapies, h) changes in the patient's life= active worker to family dependent, i) lack of health education. 
Taking into account that the stage of lung cancer in our patients was too advanced, we consider that the results were positive in terms of the degree of improvement and stabilization of the disease.

The treatment of non-small cell lung cancer must be: chemotherapy in all cases, including elder patients, radiotherapy, surgery with complete lymphadenectomy, and adyuvant chemotherapy. However, radiotherapy was not applied in the cases here analyzed due to the advanced stage of SCLC in the patients.

At the INER, the concept of Clinical Benefit is applied in some cases as one of the therapeutic objectives. This implies improvement of symptoms such as pain, the general functional state, and the loss of weight. Unfortunately, this approach is subjective.

The general conclusion of our retrospective study underlines 2 fundamental aspects related to the treatment of lung cancer in Mexico: 1) health education is a fundamental issue for understanding lung cancer therapies and prevention, 2) better results can be achieved through a multidisciplinary treatment.

\section{REFERENCES}

[1] Meerbeeck J, Surmont V. Stage IIIA-N2 NSCLC: A review of its treatment approaches and future developments. Lung Cancer 2009; 65: 257-67. http://dx.doi.org/10.1016/j.lungcan.2009.02.007

[2] Medina MF, Barrera RR, Morales JF, Echegoyen CR, Chavarría JG, et al. Primary lung cancer in Mexico City: a report of 1019 cases. Lung Cancer 1996; 14: 155-93. http://dx.doi.org/10.1016/0169-5002(96)00545-4

[3] Ruíz GL, Rizo RP, Sánchez CF, Osornio VA, García CC, et al. Mortality due to lung cancer in Mexico. Lung Cancer 2007; 58: 184-90.

http://dx.doi.org/10.1016/j.lungcan.2007.06.007

[4] Instituto Nacional de Estadística, Geografía e Informática, México (INEGI) Reporte sobre morbilidad y mortalidad en México 2004-2007.

[5] Rivera MP, Mehta AC. Initial Diagnosis of lung Cancer: ACCP Evidence-based clinical practice guidelines $2^{\text {nd }}$ ed. Chest 2007; 132: 131S-148S.

[6] Giroux LE, Lavole A, Ruppert AM, Gounant V, Wislez MM, et al. Factors associated with long-term survival of patients with advanced non small cell lung cancer. Respirology 2011; 17 : 134-43.

http://dx.doi.org/10.1111/j.1440-1843.2011.02070.x
Therasse P, Arbuck SG, Eisenhauer E, Wanders J, Kaplan $\mathrm{RS}$, et al. New guidelines to evaluate the response to treatment in solid tumors. J Natl Cancer Inst 2000; 92: 20516.

http://dx.doi.org/10.1093/jnci/92.3.205

[8] Miller AB, Hoogstraten MD, Staquet M, Winkler MD. Reportin Results of cancer treatment. Cancer 1981; 47: 207-14. http://dx.doi.org/10.1002/10970142(19810101)47:1<207::AIDCNCR2820470134>3.0.CO;2-6

[9] Pignon JP, Tribodet H, Scagliotti GV, Douillard JY, Shepherd $\mathrm{FA}$, et al. Lung adjuvant cisplatin evaluation: a pooled analysis by the LACE Collaborative Grup. J Clin Oncol 2008; 26(21): 3552-9.

http://dx.doi.org/10.1200/JCO.2007.13.9030

[10] Azzoli Ch, Baker S, Temin S, et al. American Society of Clinical Oncology. Practice Guideline Update on Chemotherapy for Stage IV Non. Small Cell Lung Cancer. J Clin Oncol 2009; 27: 6251-66. http://dx.doi.org/10.1200/JCO.2009.23.5622

[11] Thatcher N, Heighway J. Maintenance and consolidation therapy in patients with unresectable stage III/IV non-small cell lung cancer. Oncologist 2010; 15: 1034-43. http://dx.doi.org/10.1634/theoncologist.2009-0292

[12] D'Addario G, Pintilie M, Leighl NB, Feld R, Cerny T, et al. Platinum-based versus non-platinum based chemotherapy in advanced non-small cell lung cancer: a meta-analysis of the published literature. J Clin Oncol 2005; 23(13): 2926-36. http://dx.doi.org/10.1200/JCO.2005.03.045

[13] Pisters K, Evans W, Azzoli C, Kris M, Smith CA, et al. Cancer care Ontario and American society of clinical oncology adyuvant chemotherapy and adyuvant radiation therapy for stages I-IIIA resectable non-small-cell lung cancer guideline. J Clin Oncol 2007; 25(34): 5506-18. http://dx.doi.org/10.1200/JCO.2007.14.1226

[14] Rena O, Carsana L, Cristina S, Papalia E, Massera F, Lymph node isolated tumor cells and micrometastases in pathological stage I non-small cell lung cancer: prognostic significance. Eur J Cardiothorac Surg 2007; 32(6): 863-7. http://dx.doi.org/10.1016/j.ejcts.2007.09.014

[15] Zhonga W, Yanga X, Baib J, Yanga J, Manegolc C, et al. Complete mediastinal lymphadenectomy: the core component of the multidisciplinary therapy in resectable nonsmall cell lung cancer. Eur J Cardiothorac Surg 2008; 34(1): 187-95. http://dx.doi.org/10.1016/j.ejcts.2008.03.060

[16] Herpel E, Muley T, Schneider T, et al. A pragmatic approach to the diagnosis of nodal micrometastasis in early non-small cell lung cancer. J Thorac Oncol 2010; 5(8): 1206-12.

http://dx.doi.org/10.1097/JTO.0b013e3181e15cfd

[17] Le Chevalier T, Arriagada R, Pignon JP, Scagliotti GV. Should adyuvant chemotherapy become standard treatment in all patients with resected non-small cell lung cancer? Lancet Oncol 2005; 6(3): 182-4. http://dx.doi.org/10.1016/S1470-2045(05)01769-9

[18] Belcher, Goldstraw P. Is radical mediastinal dissection mandatory for curative resection of NSCLC? Eur J Cardiothorac Surg 2007; 31(1): 142-3. http://dx.doi.org/10.1016/j.ejcts.2006.10.011

http://dx.doi.org/10.6000/1927-7229.2012.01.01.9

(C) 2012 Echegoyen-Carmona et al.; Licensee Lifescience Global.

This is an open access article licensed under the terms of the Creative Commons Attribution Non-Commercial License (http://creativecommons.org/licenses/by-nc/3.0/) which permits unrestricted, non-commercial use, distribution and reproduction in any medium, provided the work is properly cited. 